\title{
Paulo Freire e educação humanista: (re)aberturas humanas na construção do Ser mais no mundo
}

\author{
Allan Diêgo Rodrigues Figueiredo* - UFPE \\ André Gustavo Ferreira da Silva** - UFPE
}

\section{Resumo}

Este artigo se propõe a refletir o lugar do ser humano na educação a partir das tessituras pedagógicas do pensamento freireano acerca da educação humanista, tomando como pontos primaciais as categorias de Inacabamento bumano e Ser mais. A investigação buscou problematizar quais as contribuições do humanismo freireano, procurando considerar o lugar do ser humano na educação. Para isso, a pesquisa mobilizou-se pelo caráter qualitativo, exploratório e percurso de levantamento bibliográfico. Por fim, compreendeu-se que a educação humanista tem como princípio conduzir os sujeitos sociais ao centro do processo reflexivo, da formação humana e de seu projeto teorético-prático que instiga homens e mulheres à tomada de consciência e à atuação no mundo. A educação humanista revela-se um percurso filosófico/libertador capaz de propor aos seres humanos novas leituras sobre mundo e a palavra.

Palavras-chave: Educação humanista, Inacabamento bumano, Ser mais, pensamento freireano.

Doutorando em Educação no Programa de Pós-Graduação em Educação (PPGEdu-UFPE), Mestre em Educação Contemporânea pelo Programa de Pós-Graduação em Educação Contemporânea (PPGEduC-UFPE), Licenciado em Filosofia pela Faculdade São Bento da Bahia. Membro do Grupo de Estudos e Pesquisas Interdisciplinar em Formação Humana, Representações e Identidades (GEPIFHRI). Bolsista FACEPE. ORCID iD https://orcid. org/0000-0002-0554-873 E-mail: allandiego_st@hotmail.com<?>

** Doutor em Educação UFPE. Professor do PPGE-UFPE. Centro Paulo Freire - Estudos e Pesquisas. Membro do Grupo de Estudos e Pesquisas Interdisciplinar em Formação Humana, Representações e Identidades (GEPIFHRI). ORCID iD https://orcid.org/0000-0001-9486-1052 E-mail: andreferreiraufpe@gmail.com 


\section{Paulo Freire and humanist education: human (re)openings in the construction of Being more in the world}

\section{Abstract}

This article proposes to reflect the place of the human being in education based on the pedagogical fabrications of Freire's thought about humanistic education, taking as primary points the categories of Human Unfinished and Being more. The investigation sought to problematize the contributions of Freire's humanism, seeking to consider the place of the human being in education. For this, the research was mobilized by the qualitative, exploratory and bibliographic survey path. Finally, it was understood that humanist education has the principle of bringing social subjects to the center of the reflective process, of human formation and of its theoretical-practical project that instigates men and women to become aware and act in the world. Humanist education reveals itself to be a philosophical / liberating way capable of offering human beings new readings on the world and the word.

Keywords: Humanist education, Human unfinished, Being more, Freire's thought.

\section{Paulo Freire y la educación humanista: (re) aper- turas humanas en la construcción del Ser más en el mundo}

\section{Resumen}

Este artículo propone reflejar el lugar del ser humano en la educación basado en el tejido pedagógico del pensamiento de Freire sobre la educación humanista, tomando como puntos principales las categorías de Inconclusión bumana y Ser más. La investigación buscó problematizar las contribuciones del humanismo de Freire, buscando considerar el lugar del ser humano en la educación. Para esto, la investigación fue movilizada por el camino de la encuesta cualitativa, exploratoria y bibliográfica. Finalmente, se entendió que la educación humanista tiene como principio llevar a los sujetos sociales al centro del proceso reflexivo, de la formación humana y de su proyecto teórico-práctico que instiga a hombres y mujeres a tomar conciencia y actuar en el mundo. La educación humanista se revela como un 
viaje filosófico / liberador capaz de ofrecer a los seres humanos nuevas lecturas sobre el mundo y la palabra.

Palabras clave: Educación humanista, Inconclusión bumana, Ser más, Pensamiento de Freire.

\section{Introdução}

Refletir a educação humanista na perspectiva freireana em prol de fundamentação do lugar do ser humano na educação apresenta seus dilemas. A sociedade contemporânea, no que concerne à educação, tem direcionado suas agendas em torno de avaliações de larga escala, resultados e processos de ensino e aprendizagem que visam a aprimorar as técnicas, o uso das tecnologias e tentativas de hegemonizar as metas para o sistema de educação. Assim, ao que parece, o projeto de humanização e o reconhecimento do processo de formação humana que contemple os sujeitos sociais-educativos em sua forma integral, dá lugar a uma educação que se pauta em números, conteúdos e vitrines de instituições de ensino com ranqueamentos.

A partir desses (con)textos surgem indagações, por ora, consideradas potentes: há lugar para pensar e vivenciar a humanização na educação? Quais os lugares dos afetos? Da formação integral? Quais as relações entre conteúdos e formação que estruturam para a escola e a sua finalidade para constituir uma sociedade educadora? Eis algumas questões que poderão propiciar a experiência do pensar a educação humanista pautando-se no pensamento freireano. Outra problematização é a que faz Arroyo (2018, p. 5): “a que grupos sociais e políticos reconhecer como humanos, educáveis, humanizáveis?" (ARROYO, 2018, p. 5). Nesta dinâmica de problematizações constitui-se este estudo.

Neste sentido, com intuito de provocar uma reflexão sobre a educação humanista, o presente estudo desenvolveu-se por meio de duas categorias freireanas: Inacabamento bumano ${ }^{1}$ e Ser mais. Assim,

No decorrer da reflexão, faremos uso de duas expressões: Inacabamento e inconclusão do ser. Segundo Freire (2011, p. 22), "o inacabamento do ser ou sua inconclusão é próprio da experiência vital”. A partir dessa afirmação, compreendemos os dois conceitos como sinônimos. 
teceram-se conjecturas a respeito de seus sentidos na compreensão das contribuições do humanismo freireano para pensar o lugar do ser humano na educação. Estruturou-se como objetivo: refletir o lugar do ser humano na educação a partir das tessituras pedagógicas do pensamento freireano acerca da educação humanista, tomando como pontos primaciais as categorias de Inacabamento humano e Ser mais.

Os itinerários metodológicos mobilizaram-se a partir de um percurso bibliográfico. Com isso, o estudo ${ }^{2}$ será puramente teórico, baseado na busca por trazer à tona a educação humanista na perspectiva freireana por meio do estudo conceitual acerca do Inacabamento bumano e o Ser mais. Para a escolha das categorias e do caminho metodológico, a reflexão em questão tornou-se pertinente por apresentar duas concepções freireanas que suscitam novos olhares e o (re)pensar os paradigmas educacionais contemporâneos. A presente investigação delineou-se em quatro partes: - O reconhecimento do Inacabamento humano como um movimento educativo-libertador; - A retomada da concepção do Ser mais como experiência do humano; - O Inacabamento humano e o processo de Ser mais: Apontamentos da realidade e fundamentação do locus do humano na Educação; e Considerações finais.

\section{O reconhecimento do Inacabamento humano como um movimento educativo-libertador na educação}

O humanismo é interpretado, historicamente, com diversas faces e apresenta múltiplas concepções do homem e do humano a partir de cada contexto e período histórico. Segundo Tuan (1982, p.144): "O uso histórico, então, permite-nos definir o humanismo como uma visão ampla do que a pessoa humana é o do que ela pode fazer". A partir desta premissa, o presente estudo será delineado a partir da compreensão de educação humanista em Freire, tomando como conceitos norteadores Inacabamento humano e Ser mais. O próprio autor reflete suas intenções acerca da educação humanista ao afirmar:

2 A presente investigação teórica foi financiada pela FACEPE. 
Uma das preocupações, enquanto pedagogo e enquanto homem, que me acompanha desde o início de minhas atividades, é exatamente esta que eu chamo de humanizante, de humanista. Quero, porém, fazer um parêntese para dizer que a minha postura humanizante não é uma postura adocicada, açucurada; a minha postura humanista não tem nada beligerantemente contra a tecnologia e contra a ciência. Eu não nego a tecnologia e nem me oponho a ela. A minha posição é sempre a de quem suspeita, de quem se pergunta [...] (FREIRE, 2017, p. 233).

Um dos pilares da antropologia freireana é a concepção de Inacabamento, que caracteriza a existência do ser humano no mundo como um ser inconcluso, um ser de aspirações (ARDUINI, 1989). Freire (2011, p. 22) afirma que "o inacabamento do ser ou sua inconclusão é próprio da experiência vital. Onde há vida, há inacabamento". O ser humano, porém, diferentemente dos outros seres vivos, é o único capaz de ter consciência acerca da sua própria inconclusão. Na pedagogia freireana, o conceito de inacabamento nasce da constatação de que o ser humano, além de ser capaz de perceber-se enquanto ser-no-mundo, é também capaz de analisar sua posição em relação a ele. Percebe-se como um ser inconcluso que tem consciência dessa inconclusão e pode, ainda, ser consciente a respeito dos elementos que o circundam e tecem a sua existência. Esta percepção de si e do mundo se dá em diferentes graus de entendimento e apreensão da realidade, relativos às diversas e diferentes condições em que esses seres humanos se encontram.

A educação, como fenômeno tipicamente humano, tem a sua origem na percepção humana acerca do seu próprio inacabamento. Sobre isso Freire (2011), por meio de sua visão humanista, entende o locus do humano na vida e, sobretudo, na educação. Acerca do entendimento de inacabamento e sua importância para a educação, Freire aborda:

O homem se sabe inacabado e por isso se educa. Não haveria educação se o homem fosse um ser acabado; é um ser na busca constante de ser mais e, como pode fazer esta autorreflexão, pode descobrir-se como um ser inacabado, que está em constante busca. Eis aqui a raiz da educação. (FREIRE, 2011, p. 27). 
Freire (2013) entende a educação em seu caráter permanentemente processual. Considera que o ser humano está ligado substancialmente ao mundo, que é mudança, e que ele mesmo se constitui numa experiência contínua de existir no espaço e no tempo, tem a sua consciência configurada por esta incompletude, que se manifesta na sua ação permanente, em busca do crescimento, da superação dos seus próprios limites e das situações-limite que vivencia, impulsionado pela vocação a Ser mais. A educação não deve se pautar ou se restringir a um dado período da existência do indivíduo, mas deve transcorrer por sua vida inteira. Por essa razão, deve ser continuamente crítica, emancipadora das amarras que impedem o crescimento individual e coletivo impostas por poderes autoritários e antidemocráticos.

Os seres humanos estão situados num mundo em mudanças, como seres inconclusivos e não limitados por determinismos. Estão apenas condicionados por uma dada situação, que é sempre passível de mudança pela ação de sua própria consciência livre. É o processo de conscientização acerca de sua "situação" que lhes permite emergir, para transformar a realidade. A respeito disso, Freire assevera:

Sendo os homens seres em "situação", se encontram enraizados em condições tempo-espaciais que os marcam e a que eles igualmente marcam. Sua tendência é refletir sobre sua própria situacionalidade, na medida em que, desafiados por ela, agem sobre ela [...] Os homens são porque estão em situação. E serão tanto mais quanto não só pensem criticamente sobre sua forma de estar, mas criticamente atuem sobre a situação em que estão (FREIRE, 2013, p.101, grifos do autor).

É necessário, portanto, pensar e refletir seriamente e com profundidade a respeito da "situação" na qual se encontram, tomando consciência subjetiva e objetiva da realidade, o que deve provocar, então, a sua práxis, orientada pela reflexão crítica, pela teoria. Este é o papel da educação na perspectiva freireana: através de uma atitude problematizadora, oportunizar um pensar crítico por meio do qual os seres humanos se descobrem em 'situação', desve- 
lando e percebendo as contradições presentes na realidade objetiva. Assim, dando-se conta da sua consciência histórica, tornam-se sujeitos das transformações que eles próprios provocam no mundo. A situação humana não é um determinante absoluto do que é o ser humano e do que ele pode ser. Pensar o ser humano simplesmente como determinado pela situação em que vive - ou mesmo como alguém dirigido por algo dado aprioristicamente - é acreditar e afirmar que existe uma limitação definitiva para o seu desenvolvimento.

É com base no fundamento antropológico do inacabamento que Freire contrapõe ao que chama de educação "bancária" uma educação para autonomia e a liberdade (FREIRE, 2013). A concepção bancária de educação não leva em consideração este caráter aberto e dinâmico do ser humano. Nela prevalece a ideia de estaticidade e permanência, que leva a pensar num imobilismo que caracteriza o processo de educação, ao fim do qual o ser humano está "acabado", cheio de conhecimentos "verdadeiros" e definitivos. Segundo esta concepção, antes de se submeter a este processo, o ser humano, quando ainda não possui estes conhecimentos - depositados por alguém que tem o domínio pleno dos mesmos, no caso, os professores - pode ser considerado um ser incompleto, que depende das orientações, conhecimentos e informações indispensáveis para que ele seja constituído de um grau aceitável de "humanidade".

Ao elaborar a crítica a esse modelo antropológico e à concepção educacional dele decorrente, Freire apresenta outro modo de pensar a educação, a qual deve ser problematizadora, que provoque a transformação, a mudança, e não aceite a realidade simplesmente como algo estático e imutável nem um futuro dado a priori, considerando que os sujeitos são seres humanos transformadores, "educáveis", abertos a seguirem permanentemente o percurso do seu vir-a-ser. Por essa razão, constata-se a condição da historicidade dos seres humanos, capazes de, a partir da consciência do próprio inacabamento, transformar a realidade, fazendo a história.

Neste sentido, Freire também apresenta uma compreensão de processo histórico sob a égide do inacabamento, isto é, da pos- 
sibilidade. O educador alerta que a compreensão que se tem sobre a dinâmica da história, se determinista ou aberta, emoldura a concepção que se tem sobre a natureza da educação. O pedagogo pernambucano (FREIRE, 2013) aponta que, quando se entende a história como possibilidade, a educação, assim, pode ser entendida enquanto espaço da utopia, do sonho, da opção e da luta, que são algumas das categorias fundamentais de uma educação libertadora, isto é, não bancária; Porquanto, é a conformação à estrutura dominante de poder, consequentemente a incorporação da ideia de processo histórico determinado por um poder superior à liberdade das possibilidades do homem, que poderiam ser características de uma educação bancária, seja à direita, seja à esquerda.

Neste sentido, o ideário freireano nos leva a refletir que o inacabamento do homem é expressão da própria abertura da dinâmica histórica. Pois, não sendo a realização de um fundamento prefixado, a realidade objetiva e histórica, que envolve o sujeito singular, é o ambiente atravessado por possibilidades que alimentam o inacabamento do próprio sujeito. Por conseguinte, não podemos pensar no inacabamento do sujeito sem levar em conta a história enquanto abertura e possibilidade. Haja vista Freire (2014) sinalizar que não se pode abordar a questão da subjetividade sem compreendê-la em sua relação dialética com a objetividade histórica; e ainda que sua noção de subjetividade se refere à existência das pessoas no mundo como inacabamento, posto que, "inacabados, se tornaram capazes de saber-se inacabados, entre os seres que se fizeram aptos de ir mais além da determinação, reduzida, assim, a condicionamento e que, assumindo-se como objetos, porque condicionados, puderam arrisca-se como sujeitos, porque não determinados". (FREIRE, 2014, p. 57).

Por conseguinte, entendendo que o humano não é somente objeto, mas, igualmente, sujeito da história (FREIRE, 2014), é importante ter em conta que a realidade vivenciada pelo ser humano no presente não é a efetividade inexorável de nenhuma lei que determine a dinâmica da história. Por conseguinte, o futuro é pos- 
sibilidade. Todavia, ao se incorporar a ideia da história como possibilidade, temos que abandonar a expectativa de desenvolvimento sempre positivo da experiência humana e civilizatória, isto é, um futuro de progresso não está garantido. Nesta ótica, Freire (2001, p. 91) claramente afirma que "o futuro não é um pré-dado". Contudo, mesmo que não se tenha garantido o desenvolvimento inexorável que aponte para a efetividade do Ser mais, o futuro também não está condenado a reprodução dos mecanismos atuais de negação do sujeito. E, é sob esta perspectiva que devemos entender a ideia de educação política e libertadora em Freire.

A inconclusão humana, característica antropológica fundamental na pedagogia freireana, é parte essencial do ato de ensinar, trazendo implicações importantes para a o perfil do educador. Também consciente de sua própria inconclusão, o educador, na relação com o educando, é alguém que se coloca aberto à mudança, à aceitação do diferente, numa atitude de disposição para o diálogo e troca de saberes, como parte de sua experiência vital. Assim, afirma-se o caráter permanente, dialógico e dinâmico da educação, em razão da finitude e inacabamento do ser humano:

A educação é permanente na razão, de um lado, da finitude do ser humano, de outro, da consciência que ele tem de sua finitude. Mais ainda, pelo fato de, ao longo da história, ter incorporado à sua natureza não apenas saber que vivia mas saber que sabia e, assim, saber que podia saber mais. A educação e a formação permanente se fundam aí (FREIRE, 2014, p.15).

Os seres humanos, portanto, como seres inacabados, conscientes de sua inconclusão, vivem em permanente busca e necessitam uns dos outros para aprender. Gadotti assevera: "Nós, seres humanos, não só somos seres inacabados e incompletos como temos consciência disso. Por isso precisamos aprender com. Aprendemos com porque precisamos do outro, fazemo-nos na relação com o outro, mediatizados pelo mundo, pela realidade em que vivemos". (GADOTTI, 2003, p. 47). Por meio da educação, os seres humanos "tornam-se humanos", se humanizam, conscientes dos 
seus limites e de suas imensas possibilidades, situados no mundo, mas não limitados absolutamente por ele, mas como sujeitos livres e capazes de ações transformadoras da realidade.

\section{A retomada da concepção do Ser mais como ex- periência do humano para a Educação}

A reflexão em torno da categoria Ser mais na obra de Freire apresenta-se de modo central, como ponto mobilizador de outras categorias no seu pensamento, tais como criticidade, homem, História, conscientização, libertação e, principalmente, Inacabamento humano. A compreensão do Ser mais posiciona o homem enquanto vocacionado à liberdade de ser pessoa no mundo, ou seja, protagonista da construção da história em diálogo com o outro numa relação mediatizada pelo mundo.

Para refletir sobre o lugar do humano e da formação humana na perspectiva de Paulo Freire, faz-se necessário recorrer à concepção freireana Ser mais, que nasce da consideração do fato de que homens e mulheres são seres históricos, abertos, livres, e trazem como caraterística original o seu inacabamento. A educação é pensada pelo autor como processo de humanização, quando afirma que "humanização e desumanização, dentro da história, num contexto real, concreto, objetivo, são possibilidades dos homens como seres inconclusos e conscientes de sua inconclusão. Mas, se ambas são possibilidades, só a primeira nos parece ser o que chamamos de vocação dos homens (...)" (FREIRE, 2013, p. 27). Esta vocação, negada na injustiça e na violência dos opressores, é afirmada no anseio de liberdade que leva à luta dos oprimidos para recuperar a humanidade que lhes foi roubada. A desumanização é uma distorção da vocação do Ser mais, que, sendo possível de se dar na história, é também historicamente passível de correção e superação na história, por uma educação que se compreende como processo de humanização.

A vocação do Ser mais é, assim, a vocação ontológica dos seres humanos, entendidos por Freire como seres inacabados e inconclusos que, conscientes do seu inacabamento, vivem numa realidade his- 
tórica aberta, dinâmica e também não concluída. Trata-se, assim, da inconclusão dos sujeitos humanos e da consciência que eles têm do fato de serem inconclusos. Segundo Freire, a educação problematizadora, diferentemente da educação "bancária", parte da consideração do caráter histórico e da historicidade dos seres humanos.

\begin{abstract}
Por isto mesmo é que os reconhece como seres que estão sendo, como seres inacabados, inconclusos em e com uma realidade que, sendo histórica também, é igualmente inacabada. $\mathrm{Na}$ verdade, diferentemente dos outros animais, que são apenas inacabados, mas não são históricos, os homens se sabem inacabados. Têm a consciência de sua inconclusão. Aí se encontram as raízes da educação mesma, como manifestação exclusivamente humana. Isto é, na inconclusão dos homens e na consciência que dela têm (FREIRE, 2013, p. 72-73).
\end{abstract}

Os seres humanos, ao tomarem consciência da realidade, apropriam-se da história, dando-se conta de que ela é passível de ser por eles transformada. Como seres históricos e inacabados, descobrem-se sujeitos não só da transformação do mundo, mas da transformação de si mesmos. As raízes da educação, como fenômeno exclusivamente humano, encontram-se nesse fenômeno, aberto e dinâmico. Fundamentada na inconclusão dos seres humanos, capazes de mudar permanentemente a realidade - também inconclusa e em constante transformação -, a educação se mostra como um que-fazer permanente. A educação, nesse sentido, "se re-faz constantemente na práxis; para ser tem que estar sendo" (FREIRE, 2013, p. 73).

A educação, concebida como processo, se caracteriza por manter sempre em jogo os polos permanência-mudança. A educação bancária enfatiza a permanência. A educação problematizadora, por sua vez, reforça a mudança (FREIRE, 2013). Os seres humanos, agindo no presente e abertos ao futuro, na busca permanente de ir sempre mais além de si mesmos, encontram na educação problematizadora o caminho que potencia a sua esperança, a sua ação revolucionária e transformadora da realidade que lhes toca viver. Não aceitam nem o passado como algo inquestionável que deve ser aceito passivamente, nem o futuro como algo já dado e con- 
dicionado, fechado, como uma fatalidade. Pelo contrário, os seres humanos devem se pensar "como seres que caminham para frente, que olham para frente; como seres a quem o imobilismo ameaça de morte; para quem o olhar para trás não deve ser uma forma nostálgica de querer voltar, mas um modo de melhor conhecer o que está sendo, para melhor construir o futuro" (FREIRE, 2013, p. 73).

A desumanização é a negação do ser, que contradiz a vocação histórica dos seres humanos, que é a busca permanente por Ser mais, por sua humanização. É nesse processo que se compreende o papel da educação, como prática da liberdade a serviço da humanização do humano. O ponto de partida deste movimento está na realidade concreta dos seres humanos, nas suas relações com o mundo, com os outros, no mundo e na realidade que lhes toca transformar (FREIRE, 2013).

A partir da problematização em torno das situações em que se encontram, os sujeitos sociais poderão mover-se no interior de um processo de formação humana em diálogo com a emancipação e dinâmicas para os enfretamentos de processos que negam a justiça social e a equidade (COELHO, 2009). Para isso, é necessário que os seres humanos não vejam essas situações como uma fatalidade, uma realidade inexorável e intransponível. Devem enfrentá-las simplesmente como um limite que os desafia, provocando a sua liberdade. Problematizar é, portanto, uma ação reflexiva em vista da formação de sujeitos sociais críticos:

Enquanto a prática 'bancária', por tudo o que dela dissemos, enfatiza, direta ou indiretamente, a percepção fatalista que estejam tendo os homens de sua situação, a prática problematizadora, ao contrário, propõe aos homens sua situação como problema. Propõe a eles sua situação como incidência de seu ato cognoscente, através do qual será possível a superação da percepção mágica ou ingênua que dela tenham. A percepção ingênua ou mágica da realidade da qual resultava a postura fatalista cede seu lugar a uma percepção que é capaz de perceber-se. E porque é capaz de perceber-se enquanto percebe a realidade que lhe parecia em si inexorável, é capaz de objetivá-la. (FREIRE, 2013, p. 74) 
Os seres humanos, ao tomar consciência de sua situação e aprofundar esta percepção, apropriam-se dela como realidade histórica, percebendo, ao mesmo tempo, que é possível mudá-la, sendo eles mesmos os agentes desta transformação. São eles que fazem a história, transformando a realidade. A educação libertadora inspira, portanto, esperança e disposição para a ação de sujeitos sociais que têm incidência na realidade, transformando-a. A respeito disso, Freire (2013, p. 74) elucida: “O fatalismo cede, então, seu lugar ao ímpeto de transformação e de busca, de que os homens se sentem sujeitos". Seres históricos, inseridos num movimento de busca, com outros seres humanos, tais sujeitos inserem-se num dinamismo de mudanças históricas e sociais, nunca vivido no individualismo e no isolamento, mas na comunhão e na "solidariedade de existires".

Esta transformação, em razão do seu caráter essencialmente aberto à dimensão comunitária da existência, não pode se dar em situações marcadas por relações de opressão, de poder e submissão, porque "ninguém pode ser, autenticamente, proibindo que os outros sejam” (FREIRE, 2013, p. 75). Tais relações são fonte de desumanização e do ser menos, tanto do oprimido quanto daquele que o oprime. A vocação ao Ser mais, no entanto, apesar de historicamente distorcida e negada em situações como estas, segue viva e pulsante no coração dos seres humanos, desafiantes do destino dado e inexorável, conscientes de que a própria história é dinâmica.

O dinamismo impulsionado por esta vocação ontológica do ser humano para o Ser mais é o que faz possível a superação das formas concretas e históricas de desumanização e alienação. Tal superação acontece no desenvolvimento do pensamento crítico e reflexivo em vista de uma atuação eficaz sobre a realidade que, sendo histórica e inacabada, pode ser mudada pela incidência da ação transformadora dos sujeitos. Ser mais é, assim, fazer-se sujeitos de seu próprio processo. A ação transformadora dos homens e mulheres sobre seu mundo tem como resultado a sua humanização (FREIRE, 2013). A educação assume um papel fundamental neste processo de humanização ou desumanização, considerando que ela 
pode tanto ser instrumento de libertação ou, ao contrário, de domesticação, quando os sujeitos se reduzem a objeto um do outro. A vocação para o ser mais, o desejo de "ir além de seus condicionantes" (FREIRE, 2011, p. 30) faz com que a ação cultural dos seres humanos para a libertação se articule com sua ação transformadora sobre a realidade. A educadora Anita Freire (2019) assim se expressa a respeito do legado de Paulo Freire em relação ao "direito ontológico do ser humano a ler e escrever a palavra", o mundo, a uma educação libertadora:

Paulo entendeu (...) que um mundo novo só poderia erigir-se de homens e mulheres SERES MAIS. Sujeitos e não só objetos da sociedade e de si mesmos, não com indivíduos "demitidos da vida", mas com pessoas SERES MAIS. Então, para chegar a homens e mulheres sujeitos de si, Paulo lutou (...) para que, além de ler e escrever a palavra, os(as) alfabetizandos/ as soubessem, criticamente, ler o mundo. Esse é o ato de conscientização, que precisa da escola oferecida pela educação formal. (FREIRE, 2019, p. 3).

O ser humano se move no tempo e no espaço para, permanentemente, atendendo à sua vocação ontológica para Ser mais, constituir a sua humanização. A pedagogia humanista de Freire, buscando favorecer a leitura e o enfrentamento de uma realidade caracterizada por grandes desigualdades sociais, econômicas e culturais, é capaz de responder aos desafios do mundo contemporâneo, pois "pela sua dimensão esperançosa, transformadora e libertadora, cumpre um papel indispensável enquanto instrumento socioeducacional de luta” (MENDONÇA, 2006, p. 38).

Em sua obra Pedagogia do Oprimido, Freire propõe o caminho da humanização pela educação, partindo da ideia de situação-limite, que descreve como "determinantes históricas, esmagadoras, em face das quais não lhes cabe outra alternativa senão adaptar-se." (FREIRE, 2013, p. 93). A partir da constatação dessas barreiras que impedem os seres humanos de realizarem a sua humanidade, deve-se empreender o caminho de superação. Segundo Mendonça (2006, p. 41), "a superação dessa condição exige que homens e 
mulheres adquiram, processualmente, uma conscientização capaz de levá-los de um ponto de máxima negatividade até um ponto de positividade". O processo pedagógico proposto, para isso, é caracterizado pela problematização, ou seja, o questionamento acerca da própria condição existencial dos sujeitos e da realidade em que estão inseridos. Freire ilustra sua proposta, comparando duas práticas pedagógicas antagônicas:

Para a prática "bancária", o fundamental é, no máximo, amenizar esta situação, mantendo, porém, as consciências imersas nela. Para a educação problematizadora, enquanto um quefazer humanista e libertador, o importante está em que os homens submetidos à dominação lutem por sua emancipação. Por isto é que esta educação, em que educadores e educandos se fazem sujeitos do seu processo, superando o intelectualismo alienante, superando o autoritarismo do educador "bancário", supera também a falsa consciência do mundo. (FREIRE, 2013, p.75).

Homens e mulheres, como seres históricos, inacabados, conscientes dos seus condicionamentos e das possibilidades de ir além deles, não podem abrir mão de serem sujeitos, atores de sua transformação, de sua humanização. Assim, afirmam e fortalecem a sua vocação para o Ser mais, a convicção radical de que os seres humanos têm um compromisso ontológico e histórico para realizar permanentemente a sua humanidade (FIGUEIREDO; VELOSO; SILVA, 2019). A história é tempo de possibilidades e não de determinismos sem horizontes. Por isso, faz-se necessário problematizar o futuro, recusando a sua inexorabilidade. Ao refletir sobre a ontologia de Freire, Glass (2013, p. 835) afirma que "o aspecto definidor da existência humana é que produzimos história e cultura ao mesmo tempo em que história e cultura nos produzem".

A vocação ontológica para o Ser mais é, portanto, o que mantém o ser humano tensionado em busca de sua permanente humanização, a experiência de assumir-se enquanto ser histórico e social, pensante e comunicante, transformador. A proposta freireana rompe com "a reificação do humano, ao pautar uma formação que não desconsidere a visão total do ser humano, mas articula saberes 
e procedimentos técnicos a uma compreensão crítica da realidade concreta" (FIGUEIREDO; ALENCAR, 2019, p. 24).

\section{O Inacabamento humano e o processo de Ser mais: Apontamentos da realidade e fundamen- tação do locus do humano na Educação}

Após a reflexão em torno do Inacabamento humano e o Ser mais, torna-se possível compreender esses dois conceitos como matrizes para se pensar uma empreitada filosófica que fundamenta a educação humanista em Freire, uma vez que "o homem pode refletir sobre si mesmo e colocar-se num determinado momento, numa certa realidade: um ser de busca constante de ser mais e, como pode fazer esta autorreflexão, pode descobrir-se como ser inacabado, que está em constante busca" (FREIRE, 2011a, p. 29). O ato de refletir sobre o mundo e acerca de si, parece possibilitar uma experiência filosófica e libertadora, mormente, quando homens e mulheres inserem-se num processo de conscientização o qual permite reconhecer os discursos, as relações de poder e ações opressoras contra a dignidade humana (FREIRE, 2011a).

Vale ressaltar que essa discussão conceitual vislumbra a formação humana e é mobilizada não apenas enquanto uma leitura da palavra, mas, sobretudo, leitura do mundo. Leituras essas compromissadas com os valores e a justiça social. Essa reflexão convida o ser humano à prática que se torna possível porque provoca reflexão acerca da experiência de estar no mundo, sendo. É por isso que convém refletir as aberturas do ser humano às buscas e ao projeto de educação que compreenda os sujeitos sociais como sendo "capazes de intervir no mundo, de comparar, de ajuizar, de decidir, de romper, de escolher, capazes de grandes ações, de significantes testemunhos (...)" (FREIRE, 2011, p. 53-54).

Com isso, a consciência e experiência do Inacabamento bumano coloca o ser humano num questionamento de lançar-se às vivências do mundo por meio de um movimento de humanização, propiciando-lhe, assim, a reflexão ética sobre si, sobre o outro e o mundo. 
Dessa forma os sujeitos sociais, engajados no processo de educação humanística, provocam a experiência filosófica de pensar e de agir em busca da libertação (FREIRE, 2013).

As compressões de Inacabamento bumano e Ser mais podem ser entendidas como inerentes uma à outra. O Inacabamento bumano está inserido no processo de Ser mais no mundo, pois a atitude de reconhecer-se aberto às experiências e aos enfrentamentos das relações opressoras são candentes numa reflexão macro em torno do Ser mais, ou seja, de quaisquer relações que violentem a dignidade humana. Ser no mundo por meio da leitura do mundo e da palavra implica entender a vida dos sujeitos educativos sendo transformada, enquanto especulação e experiência de si e das estruturas que constituem o universo social, econômico e político, no qual os sujeitos sociais, conscientes de sua posição no mundo, buscam "superar a relação de opressão, a fim de eliminar esta contradição" (FERNANDES, 2016, p. 483).

Considerando as contradições sociais que se voltam contra o projeto de humanização, Freire acredita que "não é possível fazer uma reflexão sobre o que é a educação sem refletir sobre o próprio homem" (2007a, p.27): esse ser humano comprometido com sua inconclusão e engendrado pelo espírito crítico em busca de $\operatorname{Ser}$ mais, que permite agir frente às "estruturas e processos que inibem ou impedem uma realização consciente de nossa liberdade (nossa historicidade e nossa capacidade para uma práxis crítica)" (GLASS, 2013, p. 836). Neste sentido, Freire (1986) aborda que a educação crítico-humanizadora contribui para o empoderamento dos oprimidos e aborda a importância da educação para o processo de enfrentamento social às realidades e sujeitos opressores. Com isso,

A questão do empowerment da classe social envolve a questão de como a classe trabalhadora, através de suas próprias experiências, sua própria construção de cultura, se empenha na obtenção de poder político. Isto faz do empowerment muito mais do que um invento individual ou psicológico. Indica um processo político das classes dominadas que buscam a própria liberdade da dominação, um longo processo histórico de que a educação é uma frente de luta." (FREIRE e SHOR, 1986, p. 72). 
Ao considerar as realidades educacionais e sociais no Brasil, principalmente, ao pensar um projeto de educação focado nos ideais de mercado e dos interesses de grupos, Arroyo (2002) propõe uma reflexão crítica que se aproxima da luta educativa pensada por Freire, para fundamentar a educação humanista a qual reconheça os sujeitos no interior de seus princípios como atores centrais. A partir de olhares críticos, Arroyo afirma:

\begin{abstract}
Não cabe na pedagogia escolar, apesar de ser essa infância real a que entra em milhares cada dia nas escolas públicas, trazendo-nos as marcas das condições deformadoras em que reproduzem sua existência. Marcas trazidas até na memória da pele, dos seus rostos e olhares. Crianças e adolescentes, roubados de alimentação, moradia e saúde, mas, sobretudo, roubados de sua humanidade, proibidos de ser, não apenas proibidos de ter, ler ou contar (ARROYO, 2002, p. 243).
\end{abstract}

O pensamento feireano, ao abordar o humano, propicia pensar a educação humanista fortalecida pelo conceito de alteridade. $\mathrm{O}$ Inacabamento bumano e a dinâmica de Ser mais apontam para a educação dialógica como ponte crítica que rompe com os propósitos educativos que se paute unicamente na competitividade, no egocentrismo e no isolamento dos sujeitos em seus processos de ensino e aprendizagem. Por isso, Freire se contrapõe ao individualismo e reflete que "o eu e o tu passam a ser, na dialética destas relações constitutivas, dois tu que se fazem dois eu" (FREIRE, 2013, p. 164). Ao que parece, a compreensão de alteridade na perspectiva freireana apresenta-se enquanto abertura ao outro. Entende-se desta forma que "é a 'outredade' que não-eu, ou o tu, que me faz assumir a radicalidade do meu eu" (FREIRE, 2011, p. 48).

Cabe ainda salientar que os conceitos de Inacabamento bumano e Ser mais propiciam reflexões críticas aos modos como são pensados as práticas e currículos, as políticas públicas, as estruturas de ensino e, principalmente, a formação docente, uma vez que a presente discussão conjectura acerca do ser humano e a sua formação alicerçada numa dinâmica critíco-humanizadora. Desta for- 
ma, torna-se possível entender o Inacabamento bumano no interior da constituição da formação e profissionalização docente, ou seja, o professor está sempre por ser formado, por autoformar-se, por se formar, também, nas relações epistêmicas e afetivas com seus pares. Dada esta interpretação, torna-se possível refletir a prática docente à luz do Inacabamento bumano que requer criticidade, dinâmica, dialogicidade, ação libertadora, pesquisa e problematização da própria prática, dos atores educativos envolvidos e até mesmo dos espaços-tempos onde as práticas docentes se materializam. Assim sendo, o professor torna-se um profissional movente em torno da existência de si e do outro num processo de formação humana.

A educadora Nita Freire (2019, p. 4) afirma que Paulo Freire "criou uma compreensão de educação autenticamente humanista e libertadora. Problematizadora". Neste sentido, a educação humanista propõe educar atores sociais para serem agentes de um projeto educativo-social que possibilite uma educação emancipadora centrada no ser humano; por isso, visa mobilizar a criticidade, a conscientização e as ações transformadoras na sociedade. Mas, a educação estaria somente preocupada com a transmissão de conteúdos, a formação profissional e da mão de obra que servirá aos ditames do mercado? Ou a educação estaria intentando maximizar processos de formação que visem à formação humana para uma sociedade justa a qual se alarga enquanto processo de humanização? Desses questionamentos brotam as relações conceituais entre o Inacabamento humano e a vocação ontológica para Ser mais. Nesta perspectiva, compreende-se que "o ser humano só se educa em relação com outros seres humanos. Aprendemos as artes de ser humanos, a libertação, os valores, no convívio, nas lutas coletivas" (SOUZA, 2015, p. 254).

As compreensões freireanas em questão sugerem um espaço-tempo de tensões que possibilita à educação contemporânea saídas do comodismo teórico-prático para o estado de autocrítica de suas tendências, princípios, práticas, projetos, concepções de escolas, de sociedade e de formação professores. Isso é possível, pois, segun- 
do Souza (2019, p. 189), Freire evidencia que "não basta entender e conhecer, é preciso vivenciar e experimentar as realidades 'do outro com o outro', a partir de uma atitude sensível e dialógica de não o violentar na sua cultura própria, na sua dimensão volitiva de querer, de optar, de escolher e de se expressar". A respeito da realidade do professorado, Freire (2011, p. 30) assevera que "a responsabilidade ética, política e profissional do ensinante lhe coloca o dever de se preparar, de se capacitar, de se formar antes mesmo de iniciar sua atividade docente". Dessa forma, a procura constante por compreender o Inacabamento bumano e os passos dos sujeitos educativos no processo de Ser mais, parece instaurar dinâmicas de (re)aberturas humanas que não permitem a cristalização dos seres humanos no cotidiano, mas os direcionam às contínuas mudanças de si, de olhares e experiências.

A proposta de educação fundamentada no humanismo fomenta um debate e embate teórico-prático frente aos processos de opressão que são direcionados pela proposta hegemônica de educação (FREIRE, 2019). Esta desconhece o ser humano enquanto capaz de formar-se, de participar de uma formação humana. Segue-se disse, que o pensamento freireano "contrapõe-se a segregar os Outros, os grupos sociais pobres, os trabalhadores, os oprimidos como primitivos, irracionais, sem saberes nem valores, sem leituras de mundo e de si no mundo, sem consciência política, sub-humanos, in-educáveis, in-humanizáveis" (ARROYO, 2019, p. 5).

O pensamento freireano acerca do ser humano também possibilita pensar na dinâmica da história e da educação forjada extra-muros das escolas e, que perpassa a dinâmica e organização dos sujeitos coletivos, como por exemplo, a participação ativa dos movimentos sociais em defesa da democracia. Esses movimentos de luta social são fomentados pela conscientização de que "é por esses caminhos que o Movimento Popular vai inovando a Educação" (FREIRE; NOGUEIRA,1989, p. 66). Com isso, não basta pensar que a educação humanista, a partir dos conceitos discutidos - Inacabamento bumano e Ser mais - propõem reflexões críticas somente aos contextos da educação escolar. 
A contribuição do pensamento humanista, a partir de Freire, também contempla as realidades dos movimentos sociais quando luta pelos lugares de homens e mulheres na sociedade. É neste sentido que Freire (2014, p. 63) se refere à "marcha dos sem-teto, dos sem-escola, dos sem-hospital, dos renegados; a marcha esperançosa dos que sabem que mudar é possível". Assim, compreende-se que os sujeitos coletivos, fortalecidos pela educação crítica-humanizadora, tornam-se capazes de pensar que "a democracia demanda estruturas democratizantes e não estruturas inibidoras da presença participativa da sociedade civil no comando da res-pública” (FREIRE, 2014, p. 40).

Assim, a proposta da educação humanista reconhece que a libertação se constrói no horizonte da esperança e da utopia por projetos educativos que permitam a leitura crítica da realidade e a análise o mundo (FREIRE, 2013). O mundo não é estático, mas precisa ser transformado no decorrer da história por sujeitos que tenham consciência do inacabamento humano, do mundo e, mormente, do conhecimento (FREIRE, 2013). Por isso, a educação humanista se desenvolve pela busca constante pela humanização dos atores educativos que compõem a sociedade.

Segundo Haddad (2019, p. 14), a proposta freireana de educação implica a sociedade a um "comprometimento ético com os oprimidos e o seu compromisso com a construção de uma sociedade justa, humanizada; uma sociedade onde não se pode ter uma postura neutra, em particular em sociedades de classe como a nossa, onde é profunda a desigualdade social". A educação humanista supõe uma responsabilidade ética, que não pode se afastar do seu compromisso histórico por justiça social. Em suma, Freire aborda que ser e estar no mundo, ou seja, a existência "não pode ser muda, silenciosa, nem tampouco pode nutrir-se de falsas palavras, mas de palavras verdadeiras, com que os homens transformam o mundo" (FREIRE, 2013, p. 81).

Para Freire (2013) o mundo é inacabado e o ser humano também. Desse modo, o processo de Ser mais no mundo perpassa 
a vida inteira dos sujeitos históricos. Com isso, os posicionamentos sociais, políticos e discursivos dos sujeitos sociais frente às investidas opressivas, possibilitaram ao ser humano vivenciar a compreensão de Inacabamento humano como atitude filosófica/libertadora de forma que os seres humanos estejam imbuídos da práxis como forma de vida e (re)existência. Neste sentido, a educação que em seu interior preza o lugar primacial do humano, baseia-se na formação de anunciadores da vida educativa e denunciadores de denegações de direitos humanos, sociais e políticos. Vê-se com isto que a consciência do Inacabamento bumano e das vivências de Ser mais possibilitam a atitude filosófica/libertadora que "não apenas fala do que pode vir, mas, falando de como está sendo a realidade, denunciando-a, anuncia um mundo melhor (FREIRE, 2014, p.121).

\section{Considerações finais}

Ao propor uma investigação teórica acerca do Inacabamento bumano e do processo de Ser mais como categorias fundantes para um movimento filosófico de (re)pensar o humano na Educação/ Mundo, compreendeu-se que a educação precisa colocar no seu centro as mulheres e homens os quais dão sentido à existência do ato de educar. Deste modo, Freire aborda a categoria de Inacabamento humano apontando para as (re)aberturas dos seres humanos no mundo. E quando se considera essa questão, essas aberturas atravessam, perpassam e inquietam as atitudes dos sujeitos que mobilizam os processos de ensino e aprendizagem. Assim, entende-se que o ato de reconhecer o Inacabamento humano possibilita, também, (re)aberturas para (re)Educações, sobretudo, ao considerar a educação como um movimento humanista-filosófico suscitado dentro do ser humano, uma experiência que aprofunda os sentidos e a dignidade de ser humano na educação.

As categorias Inacabamento humano e Ser mais, constantes no corpus teórico da concepção de educação de Paulo Freire, revelam-se muito pertinentes para pensar a escola e as práticas educativas contemporâneas. Passados mais de 50 anos da publicação de Peda- 
gogia do Oprimido, com sua aposta por uma educação libertadora, o mundo viveu grandes transformações, as sociedades tornaram-se mais complexas do ponto de vista da economia e da política e as desigualdades sociais se aprofundaram, agravando-se o quadro de opressão e exploração de multidões de seres humanos por uma elite econômica que lhes nega os direitos básicos à vida e à dignidade. Esta realidade, no Brasil, manifesta-se de modo assustador. A educação, apesar de experiências significativas de práticas pedagógicas libertadoras consolidadas em todo o país, encontra-se, lamentavelmente, marcada por teorias e práticas que sustentam as estruturas opressoras, excludentes, que continuam negando aos oprimidos de hoje a sua humanidade. Contudo, por ser possibilidade, a dinâmica da sociedade brasileira não está condenada a ser a história da reprodução dessas estruturas.

Olhando este contexto, e não perdendo de vista o potencial político da educação libertadora, constata-se a urgência de pensar uma educação humanizante, que supere a visão tecnicista e elitizante, marcada pelo incentivo à competitividade e ao individualismo, obediente aos ditames do mercado e a serviço da exploração dos seres humanos que considera descartáveis. A pedagogia proposta por Paulo Freire, ao colocar no centro a vida do ser humano, aberto, inacabado, vocacionado ontologicamente a Ser mais, apresenta-se como o caminho para a consolidação de uma educação que se coloca como locus de humanização, como experiência libertadora, grávida de esperança, geradora de seres humanos conscientes da sua capacidade e autonomia para transformar a si mesmos e o mundo.

O processo de Sermais não se constitui apenas como tessituras reflexivas, mas como um movimento de buscas, (re)existências, de (re)construções, de enfrentamentos, tomando como passos de transformação a vida humana que se faz no/com o processo de formação humana. Pensar a educação humanista a partir dos dois conceitos estudados tensiona as estruturas, organização, objetivos da educação. Assim, permite um repensar constante que acompanha os itinerários dos sujeitos enquanto seres inconclusos. 
Coloca a educação no percurso dos inconclusos, propondo à própria educação um fazer-se constante que reconhece a realidade dos sujeitos educativos no mundo.

A finalidade humanista da educação na perspectiva freireana é humanizar. Por isso, não é possível pensar um processo educativo sem a conscientização e a criticidade que mobilizam os seres humanos à transformação social. Desse modo, os conceitos de Inacabamento humano e Ser mais se apresentam como arcabouços críticos-humanizantes que propiciam o fazer-se e o (des)construir-se da educação, sobretudo, quando esta se afasta do sentido etimológico da palavra educação: educare - conduzir para fora. E este ato de conduzir é a relação de comunhão entre rostos educativos que se reconhecem pelo diálogo no encontro de seres humanos em formação do Eu com o Tu na dinâmica do Nós.

\section{Referências}

ARROYO, Miguel G. Ofício de mestre- Imagens e auto-imagens. $6^{\mathrm{a}}$ ed., Rio de Janeiro, 2002.

ARROYO, Miguel G. Paulo freire: outro paradigma pedagógico? Dossiê - Paulo Freire: O Legado Global. Educação em Revista. v.35. Belo Horizonte: UFMG, 2019. Disponível em: https://orcid.org/0000-0002-3702-2057. Acesso 10.04.2020.

ARDUINI, Juvenal. Destinação antropológica. São Paulo: Edições paulinas, 1989.

COELHO, Maria Inês de Matos. Por que a educação e a formação humana na contemporaneidade? In: COELHO, Maria Inês de Matos; COSTA, Anna Edith Bellico da (org.). A educação e a formação humana: tensões e desafios na contemporaneidade. Porto Alegre: Artmed, 2009, p. 15-47.

FERNANDES, Sabrina. Pedagogia crítica como práxis marxista humanista: perspectivas sobre solidariedade, opressão, e revolução. Educ. Soc., Campinas , v. 37, n. 135, p. 481-496, June 2016 . Disponível em: http://www.scielo.br/scielo. php?script $=$ sci_arttext\&pid $=$ S0101-

FIGUEIREDO, Allan Diego Rodrigues; ALENCAR, Maria Fernanda dos Santos. Paulo Freire e a pedagogia do MST: caminhos para (re)pensar a formação humana. In: Revista Debates Insubmissos, Caruaru, PE. Brasil, Ano 2, v.2, 
no 4. Edição Especial. 2019. Disponível em: https://periodicos.ufpe.br/revistas/ debatesinsubmissos/

FIGUEIREDO, Allan Diêgo Rodrigues; VELOSO, Keycie; SILVA,Vanessa Alves da. O livro-corpo freireano: tessituras de libertação, utopias e esperança. In: Educação no Século XXI, vol. 34. Diversidade. Belo Horizonte: Poisson. 2019. Disponível em: https://www.poisson.com.br/livros/educacao/volume34

FREIRE, Nita. O legado da obra de Paulo Freire para a educação global contra-hegemônica. Dossiê - Paulo Freire: O Legado Global. Educação em Revista. v.35. Belo Horizonte: UFMG, 2019. Disponível em: https://orcid.org/0000-00030581-1809. Acesso em 12.04.2020.

FREIRE, Paulo. Pedagogia da Esperança: um reencontro com a pedagogia do oprimido. 1a . Ed. Rio de Janeiro: Paz e Terra. 1992.

FREIRE, Paulo. A educação na cidade. São Paulo: Cortez. 5a . Ed. Dez. 2001.

FREIRE, Paulo. Educação e mudança. 36ª ed. Rio de janeiro: Paz e Terra, 2011a.

FREIRE, Paulo. Pedagogia da Autonomia: saberes necessários à prática educativa. 43ª ed. São Paulo: Paz e Terra, 2011.

FREIRE, Paulo. Pedagogia da Indignação: cartas pedagógicas e outros escritos. $5^{\text {a }}$ ed. São Paulo: Paz e Terra, 2014.

FREIRE, Paulo. Pedagogia do Oprimido. Rio de Janeiro: Paz e Terra, 2013.

FREIRE, Paulo. Pedagogia da Tolerância. Rio de Janeiro: Paz e Terra, 2017.

FREIRE, Paulo. Política e Educação. 9a ed. São Paulo: Paz e Terra, 2014.

FREIRE, Paulo. Professora sim. Tia não: Cartas a quem ama ensinar. São Paulo: Olho D'água, 1995.

FREIRE, Paulo; NOGUEIRA, Adriano. Que fazer: teoria e prática em Educação Popular. Petrópolis: Vozes. 1989.

FREIRE, Paulo; SHOR, Ira. Medo e ousadia: O cotidiano do professor. Trad. Adriana Lopez. $1^{\mathrm{a}}$ ed. Rio de Janeiro: Paz e Terra. 1986.

GADOTTI, Moacir. Boniteza de um sonho: ensinar e aprender com sentido. Novo Hamburgo, RS: Editora da Feevale, 2003. 
GLASS, Ronald David. Revisitando os fundamentos da educação para a libertação: o legado de Paulo Freire. Educ. Real., Porto Alegre, v. 38, n. 3, p. 831 851, Set. 2013. Disponível em: http://www.ufrgs.br/edu_realidade

HADDAD, Sérgio. Política, educação e atualidade do pensamento freiriano. Dossiê - Paulo Freire: O Legado Global. Educação em Revista. v.35. Belo Horizonte: UFMG, 2019. Disponível em: https://orcid.org/0000-0002-6243-1813. Acesso 12.04.2020.

MENDONÇA, Nelino José Azevedo de. A humanização na pedagogia de Paulo Freire. Dissertação de Mestrado. Universidade Federal de Pernambuco UFPE, Recife, 2006.

SOUZA, Ana Inês (Org). Paulo Freire: Vida e obra. São Paulo: Expressão popular, 2015.

SOUZA, Rogério Luiz de. O pensamento de Jacques Maritain e de Emmanuel Mounier no campo católico brasileiro e a educação libertadora de Paulo Freire. In:Revista Brasileira de História. São Paulo, v. 39, nº 82, 2019.

TUAN, Yi-Fu. Geografia Humanística. In: CHRISTOFOLETTI, A. (Org.). Perspectiva da Geografia. São Paulo: Difel, p. 143-164, 1982. 